\title{
Weighing up crime: The overestimation of drug-related crime
}

Published in Contemporary Drug Problems, 2008, Volume 35, Issue 2/3, page 265 Alex Stevens

\begin{abstract}
Background: It is generally accepted that harms from crime cause a very large part of the total social harm that can be attributed to drug use. For example, crime harms accounted for $70 \%$ of the weighting of the British Drug Harm Index in 2004. This paper explores the linkage of criminal harm to drug use and challenges the current overestimation of the proportion of crime that can be causally attributed to drug use. It particularly examines the use of data from arrested drug users to estimate the quantity of drug-related crime.

Method: Multivariate, secondary analysis of data from the British Offending, Crime and Justice Survey is used to test the hypothesis that drug users are over-represented in arrest data, compared to other offenders.

Results: It is found in logistic regression that the strongest predictor of arrest was not the frequency or type of offending, but whether an offender was in work or education. Offenders who have used illicit drugs were over two times as likely to be arrested as those who did not, even taking employment status and the type and frequency of offending into account.

Conclusion: Current methods for estimating drug-related crime endanger the validity of measurements of drug-related harm, with damaging consequences for the analysis of drug policy and the stigmatisation of drug users.
\end{abstract}




\section{Key words:}

drugs, crime, estimation, policing, cost 


\section{Introduction}

Developments in UK drug policy since 1998 have been heavily influenced by concerns about drug-related crime (Duke, 2006; Stevens, 2007). For example, the Director of the National Treatment Agency for Substance Misuse has been quoted as saying "[a]s drug misuse is now perceived largely as a crime problem rather than a public health or individual health and welfare issue, the role of treatment has to be justified by the contribution it can make to crime reduction" (Hayes, quoted by Nolan, 2002: 97). The problem of drug-related crime has taken statistical form in measures that attempt to capture the cost of drug-related crime and, importantly, the share of all drug-related harm that is represented by crime. It has been estimated (although with some caution) that drug-related crime imposed economic and social costs of $£ 13.9$ billion in 2003/4 in England and Wales (Gordon, Tinsley, Godfrey, \& Parrott, 2006). Earlier findings on these costs (Godfrey, Eaton, McDougall, \& Culyer, 2002) informed the development of the Drug Harm Index (DHI, MacDonald, Collingwood, \& Gordon, 2006; MacDonald, Tinsley, Collingwood, Jamieson, \& Pudney, 2005).

The DHI is used by the British government, through the Public Service Agreement on illegal drugs, to measure the effectiveness of the official drug strategy. Drug-related crime is heavily weighted in the DHI. For 2004 , over $70 \%$ of the value of the index was contributed by indicators of crime, with over $30 \%$ coming from domestic and commercial burglary (MacDonald, Collingwood, \& Gordon, 2006). This means that one of the main means by which the government measures the impact of its drug policy is heavily influenced by changes in crime. 
This article explores how criminal harm has been linked to drug use and presents evidence that suggests that the proportion of crime that can be causally attributed to drug use has been exaggerated in political debate, in Home Office reports and in indicators such as the DHI. This overestimation is important in influencing both the focus of UK drug policy and the prospects for reducing the criminalisation of drug users.

The article begins by critically analysing the methods that have been used to calculate the cost of drug-related crime and its weighting in the measurement of changes in drug-related harm. It explores the bases of these calculations in NTORS (the National Treatment Outcome Research Study) and New-ADAM (the New English and Welsh Arrestee Drug Abuse Monitoring). It shows how the methods of these studies lead to the overestimation of both the number of offences by problematic drug users and their causal attribution to drug use. They extrapolate data from captive populations of drug users, either in treatment or police custody, while ignoring that neither treatment patients nor police arrestees provide representative samples of drug users or offenders. In order to illustrate this problem, the article develops the hypothesis that drug users are over-represented in populations of arrestees by reference to the literature on police discrimination, and then tests this hypothesis using data from the Offending, Crime and Justice Survey. The implications of the over-estimation of drug related crime are finally discussed.

\section{The estimation of drug-related crime}


Widely varying estimates of the scale of drug-related crime have been made. For example, in British parliamentary debates on drug policy, such estimates have ranged from $20 \%$ to $70 \%$ of crime being drug-related (Stevens, 2006).

\section{Drugs, crime and causality}

Given the level of uncertainty, and the political importance of the issue, it is not surprising that the Home Office has attempted to produce estimates of the scale of drug-related crime. The two main attempts have been the estimates done by a team at the University of York (Godfrey, Eaton, McDougall et al., 2002; Gordon, Tinsley, Godfrey et al., 2006) and the Home Office's DHI (MacDonald, Collingwood, \& Gordon, 2006; MacDonald, Tinsley, Collingwood et al., 2005). Although both teams acknowledge some of the difficulties in making these estimates, both their attempts rest on a fundamental assumption; that it is the drug use of these offenders that causes their crime and so is the factor to which the cost and weighting of these crimes can be attributed. Godfrey et al (2002) base their assumptions on the numbers of crimes reported by members of the NTORS sample (Gossop et al 1998). The costs of these crimes are estimated and all of them are described as a cost of drug use. This assumes that none of these crimes would have occurred without these offenders' use of drugs and that their costs can therefore be causally attributed to drug use. Although it takes a different approach to the measurement of the proportion of crime that is drug-related (see below), the DHI also defines "drug-related crime as that committed by serious drug users" (i.e. those who have used heroin, cocaine or crack in the month previous to the offence, MacDonald et al, 2005: 7). It again assumes that all these drug users' crimes are directly caused by their drug use. 
This assumption is unfounded. Da Agra (2002: 30) summarises the available research and argues that " $[\mathrm{t}]$ here is no causal relationship between drugs and crime. There is a complex system of connections... [which is] irreducible both to drug addiction and to delinquent lifestyle." While it is true that many dependent drug users report that they have committed offences to get money to buy drugs, there are several other potential links between offending and drug use which play a part in this complex connection. These were listed by Russell (1994) in a report which led to the development of English Drug Treatment and Testing Orders. They include:

- Drug driven - the 'economic-compulsive' (Goldstein, 1985) model of drug users committing crimes in order to fund their drug habit.

- Disinhibition/aggression - the 'psycho-pharmacological' (Ibid) model, in which the effects of drug use increase aggression and reduce the inhibitions that prevent offending.

- Market related offending - the 'systemic' (Ibid) model of crime being generated through the operation of the illegal trade in drugs.

- Drug law crimes - e.g. possession, production, dealing and trafficking of illicit drugs.

- Co-existence -crime and drug use may be done by the same people without any direct causal link.

- Crime pre-exists - for most offenders, their crimes began at an earlier age than their drug use.

- Crime-enabled drug use - crime provides funds for non-dependent drug use that would not otherwise have occurred. 
- Underlying social problems - crime and drugs are linked through the, often deprived, social context in which both take place.

- Deviance disavowal - retrospective rationalisation by offenders who wish to minimise responsibility for their crimes.

The idea that the crimes of recent users of heroin and cocaine are caused by their drug use reflects a limited range of the possible explanations of the link between their drug use and their offending. Some studies plausibly suggest that offending tends to accelerate during periods of frequent and dependent drug use (e.g. Anglin \& Speckart, 1988; Parent \& Brochu, 2002). However, other studies have suggested that some users of heroin and cocaine can control their use and avoid other offences (Cohen \& Sas, 1994; Shewan \& Dalgarno, 2006; Warburton, Turnbull, \& Hough, 2005; Zinberg, 1984). The assumption on drug-related crime which is shared by both the University of York and DHI approaches exclusively relies on a direct causal link from drug use to crime. It therefore follows the tendency in contemporary discourse on drug-related crime, noted by Seddon (2006), to divorce both crime and drug use from their social context and to ignore several of the possible linkages between them.

\section{Extrapolating from drug users in treatment}

Even if this assumption of causality were to hold, there would still be problems with other assumptions made by each of the approaches. The most recent calculation of the cost of drug-related crime (Gordon, Tinsley, Godfrey et al., 2006) has been updated in the light of another Home Office estimate that there were 327,466 problematic drug users in England and Wales in 2003/4 (Singleton, Murray, \& Tinsley, 2006). 
Problematic drug use is defined as "[u]se of opiates and/or the use of crack cocaine" (Ibid: 9). As noted above, the cost estimate is based on two extrapolatory assumptions, based on the NTORS sample. Participants in the NTORS study were asked about their offending in the three months previous to entering treatment for drug dependence. The first extrapolatory assumption is that all problematic drug users who are not in treatment offend at the same mean rate as these people. The second is that they do so over a full year, as opposed to the three months that NTORS asked about.

Addiction severity has been found to be a predictor of treatment seeking (Falk \& Tonkin, 2001). People who do not experience severe problems with their drug use are less likely to seek (or be ordered into) treatment. So it is likely that the people who entered treatment in NTORS had, on average, more severe drug-related problems (including offending) than the whole group of people who have used crack or heroin in the year. This challenges the first extrapolatory assumption made by Godfrey et al. The second is challenged by the available evidence on the temporal pattern of offending by problematic drug users. One of the first studies of the effect of drug treatment on crime noted that offending tended to peak in the months before treatment entry (McGlothlin, Anglin, \& Wilson, 1977). Again, this suggests that treatment entry tends to follow particularly intensive periods of drug use and offending. More recently, data from NTORS itself has confirmed this pattern (Gossop, Trakada, Stewart, \& Witton, 2006). This means that it is unsafe to extrapolate to a whole year from offending in the three months prior to treatment entry, even for the NTORS sample (let alone for the whole population of people who have used crack or heroin). 
A final challenge to the use of the NTORS sample as a basis for the estimation of total-drug-related crime comes from the distribution of the frequency of offending in this group. This was highly and positively skewed. Thirty-nine per cent of the intake sample $(n=1,075)$ reported no offending at all in the previous three months (Gossop, Marsden, Stewart, Lehmann, Edwards, Wilson et al., 1998). The mean number of acquisitive crimes reported was 21.34, with a standard deviation of 73.31 (Gossop, Marsden, Stewart, \& Kidd, 2002). This implies that a small number of highly active offenders within the sample dragged the mean rate of offending upwards. The distribution of offending in the whole population of heroin and cocaine users is likely to be even more positively skewed. For the reasons noted above, it is likely to include a smaller proportion of highly active offenders, and a longer tail of non-offenders. This again suggests that it is unwise to extrapolate the mean from the NTORS sample to the whole population of problematic drug users.

These criticisms of the York estimates rest on the assumption that the offending of drug users in treatment (in the NTORS sample) is not representative of all users of heroin and crack. The Office for National Statistics' 2000 Survey of Psychiatric Morbidity (Singleton, Bumpstead, O’Brien, Lee, \& Meltzer, 2001) did ask its sample of 8,886 people (aged between 16 and 74 in Britain) about their mental health, substance use and treatment, but data are not available about their level of offending. The researchers classified $3.7 \%$ of the respondents as drug dependent. Only $17 \%$ of them had used any type of day care service in the past year. This suggests again that people in treatment are unlikely to be representative of the whole population of people who are using and having problems with certain drugs. 
When first published, the University of York estimate was cautiously presented as an “exploratory tool" (Godfrey, Eaton, McDougall et al., 2002: 8). Nevertheless, it has been used in informing policy. The DHI represents a more ambitious attempt to measure the effect of policy. In the DHI, the estimated cost of drug-related crime is used to weight the proportion of the index that will be contributed by the annual change in crime (MacDonald, Tinsley, Collingwood et al., 2005). The steps involved in calculating the cost of drug-related crime are:

A. Estimate the total number of offences.

B. Estimate the proportion that is drug-related.

C. Use A and B to calculate the volume of drug-related crimes.

D. Estimate the unit cost of each of these crimes

E. Multiply C by D to calculate the total cost of drug-related crime.

The authors of the DHI acknowledge that each of the stages of estimation (A, B and D) is problematic. The analysis presented here focuses on stage B: the estimation of the proportion of crime that is drug-related. As noted above, the DHI assumes that all crime that is committed by "serious drug users" is caused by their drug use and would not have happened if they were not using drugs. The reports of the DHI do not directly report the proportions of crime that are estimated to be drug-related. However, the number of drug-related burglaries and robberies that were reported as drug related in the original DHI for 2003 (MacDonald, Tinsley, Collingwood et al., 2005) represented approximately $54 \%$ and $61 \%$ respectively of the total estimates of these crimes calculated from the 2003/4 British Crime Survey (Dodd, Nicholas, Povey, \& 
Walker, 2004). The DHI seems to assume that a clear majority of both burglary and robbery is caused by drug use.

The DHI drug-related proportions are based on the New-ADAM study, which involved drug testing and interviewing arrestees at purposively selected custody suites (Bennett, 1998, 2000; Bennett, Holloway, \& Williams, 2001). This study suggested that large proportions of arrestees reported recent illicit drug use. However, in multivariate analysis of rates of drug use and ten categories of offending using the New-ADAM data, it was discovered that reports of drug use were a significant predictor of higher rates of only certain kinds of crime, and that significant relationships were only present for certain types of drug. Heroin use was only significantly associated with the frequency of shoplifting, while crack use was significantly associated only with the frequency of fraud, handling stolen goods and drug supply offences. Cocaine use was not associated with higher rates of any offence. And the frequency of burglary was not predicted by any type of drug use (Bennett \& Holloway, 2005). Even before we question the representativeness of arrestee samples, this casts doubt on the causal attribution of crime - and especially burglary, which contributes the largest portion of the weighting of the DHI - to drug use.

The New-ADAM study has well-advertised limitations ${ }^{1}$. The authors of the DHI acknowledge some of them. They place their faith in the more recent, annual Arrestee Survey to give a more valid measure of the proportion of crime that is drug-related.

\footnotetext{
${ }^{1}$ For example, the study's authors warn that "[t]he sampling method does not provide a nationally representative survey of arrestees, and the results should not be applied generally beyond the specific eight sites and the specific times in which the survey took place" (e.g. Holloway, Bennett, \& Lower, 2004). This and other limitations were highlighted by Stimson et al (1998).
} 
However, there are problems with the use of data from arrestees that are wider than just the small and selective sample of sites in the New-ADAM study.

\section{Arrestees as a sample of offenders}

Few criminologists would argue that arrestees form a random, representative sample of offenders, yet this is what the DHI assumes. Its estimate, which is based on arrestees, relies on the unfounded assumption that they form an unbiased sample of offenders. As Young (2004) has reminded us, this problem was highlighted by one of the founders of quantitative criminology. Quetelet (1842: 82) who wrote that, in the absence of an invariant ratio between crimes known and crimes committed, all statements on crime would be "false and absurd". He went on to note his astonishment that the ratio had not yet been validated. His astonishment would continue today, for there is still no way to calculate the precise ratio between the offences which are recorded and detected and the actual number of crimes, which remains a "figure known only to Mephistopheles" (Reiner, 2000a: 77). The same is true of the ratio between arrested and unknown offenders. Since Quetelet's time, knowledge has developed on why an invariant ratio between known and actual offenders does not exist in reality.

It is a basic finding of research on police practice that officers exercise discretion when choosing whom to arrest. Actions that could be defined as criminal are widespread throughout society (Karstedt \& Farrall, 2006). Police discretion in deciding which actions and people to target can easily tip over into discrimination, 
and often does (Fielding, 2005). Reiner (2000b) lists five types of discrimination that will inflate the presence of some social groups in crime statistics. They $\operatorname{are}^{2}$ :

1. Categorical discrimination - the choice to treat persons differently purely on account of their membership of a certain group, regardless of the relation of this group to crime.

2. Statistical discrimination - the choice to treat persons differently on the basis of characteristics which have been statistically associated with the group to which they belong. This is especially likely to operate where, as is the case in England and Wales, the police have targets to meet, as some groups offer greater numbers of detections and "cases brought to justice" per contact made and form filled in.

3. Transmitted discrimination - police acting differently towards members of a group due to the attitudes and information that are passed to them by members of the public.

4. Interactional discrimination - this occurs when members of a group tend to respond differently towards the actions of the police, and so incite a different response.

5. Institutionalised discrimination - the unintended discriminatory outcome of policies and practices that apply to all but have unequal consequences due to structural inequalities. This type of discrimination was characterised by the Stephen Lawrence inquiry as "unwitting" (Macpherson, 1999: para. 34).

Discrimination may also arise from the fear of "strain" that powerful and well connected offenders are able to place on organisations that attempt to scrutinise them

\footnotetext{
${ }^{2}$ He takes the first two types from the work of Banton (1983).
} 
(Chambliss, 1976) and from the feelings of "moral indignation" that certain groups and behaviours inspire in police officers (Young, 1971). Ideas on police

discrimination have been most commonly tested in regard to ethnicity (e.g. FitzGerald, Hough, Joseph, \& Qureshi, 2002; Waddington, Stenson, \& Don, 2004). The types of discrimination listed above may also apply to a different social group that is also visible, stigmatised and perceived to have high rates of offending, whose members are often truculent when questioned, who tend to be recruited from the lowest social ranks, who are not wealthy enough to pay tough and persistent lawyers and who take part in activities that many police officers would characterise as immoral. These are people who display the characteristics of problematic drug use, which are often visible to the police and public in the forms of homelessness, shabby dress, visibly poor health, sedated or agitated movement when intoxicated and public use of drugs and alcohol. For example, in a recent study with drug injectors in South Wales, they reported being very frequently stopped and searched by the police, to whom they are highly visible (Rhodes, Watts, Davies, Martin, Smith, Clark et al., 2007).

From the available evidence on policing, we can construct the hypothesis that drug users who offend are more likely to be arrested than other offenders. According to the Social Science Citation Index, no study has explicitly set out to test this hypothesis against the rate of arrest of illicit drug users. But it is possible to do so using recently released data from the Offending Crime and Justice Survey (OCJS).

\section{The over-representation of drug users in arrestee data}


The OCJS is a household survey of a random sample of around 5,000 people in

England and Wales (Budd, Sharp, Weir, Wilson, \& Owen, 2005). The data from the 2004 sweep of this survey, which included people aged 10-25 years old, was obtained from the UK data archive at the University of Essex. It contained 1,341 respondents who reported committing any offence in the past year. Data on arrest was missing for 14 respondents. Of the remainder, $6.3 \%$ reported that they had been arrested in the previous year $^{3}$. Table 1 shows the characteristics of the available sample ${ }^{4}$.

\section{Table 1 about here}

Table 2 shows the bivariate association, in cross-tabulation, between various selfreported characteristics of these offenders and their reporting of being arrested (these variables were chosen on the basis that they are likely, from previous theoretical and empirical research to be associated with arrest $)^{5,6}$.

Reporting violent offending and prolific offending were significantly associated with being arrested. However, other variables - including drug use, employment/educational status, a history of truancy and having friends in trouble with the police - were more strongly associated with the likelihood of arrest than were offending variables. In this bivariate analysis, there seems to be a clear overrepresentation of drug users in the group of arrestees. Over $9 \%$ of those who reported

\footnotetext{
${ }^{3}$ Only 6 people were arrested only for drug possession.

${ }^{4}$ All analyses were carried out after applying the weighting which was incorporated into the dataset in order to ensure the representativeness of the sample, with correction for sampling probability and non response. The sizes of the sample for each test (n) are reported from the unweighted data.

${ }^{5}$ Age was dichotomised around the median of 16 in order to avoid the problem of linearity in the logit in the later logistic regression (which was discovered using the Box Tidwell approach).

${ }^{6}$ Ethnicity was dichotomised with 1 representing black, black British or mixed and 0 representing the other categories. This was done because the black and mixed categories would be expected, from previous research, to have higher risks of arrest than the other groups.
} 
any illicit drug use also reported that they had been arrested, compared to $4 \%$ of those who reported no illicit drug use. Put another way, $65 \%$ of those who reported arrest also reported drug use, compared to the $35 \%$ of the arrestees who did not report any drug use. These proportions can be compared to the data from the Arrestee Survey. The proportion of self-reported arrested offenders who also reported using drugs in this OCJS sample was the same as the $65 \%$ of sampled arrestees aged 17-24 who reported use of any drug in the month previous to arrest in the 2003/4 Arrestee Survey (Boreham, Fuller, Hills, \& Pudney, 2006). This proportion is again much higher than the proportion of arrestees in the OCJS sample who did not report drug use, suggesting again that drug users are over-represented in arrest figures by comparison with their prevalence among self-reported offenders in a random, household survey.

\section{Table 2 about here}

In order to test the relative influence of these variables on the likelihood of arrest, while taking the effect of the other variables into account, a logistic regression analysis was carried out, with self-reported arrest in the previous year as the dependent, outcome variable ${ }^{7}$. The variables in the model were tested for multicollinearity, which was not present. Variables which were not significant in the in cross-tabulation (see table 2) were excluded from the model. The remaining variables were entered into the model backward stepwise in order to explore which of them contributed to the prediction of whether a respondent reported being arrested.

\footnotetext{
${ }^{7}$ Logistic regression provides an estimate of the likelihood of reporting arrest for people in each category of the independent, predictor variables, while taking into account the influence of the other variables in the model. This likelihood is reported in the form of the odds ratio, which indicates the odds of arrest for a person who is coded as belonging to the listed category of the predictor variable, relative to a person who is in the opposite category. For example, in table 3, male respondents were 3.5 times more likely to report being arrested than females, while holding the other independent variables constant.
} 
Table 3 gives the results of the final model. Of the original sample of self-reported OCJS offenders, 307 were excluded from this model due to missing data on one or more of the variables in the model. The value of Nagelkereke R Square (which gives an approximate measure of the proportion of variance in whether a person reported arrest that is explained by the variables in the model) was relatively low at 0.18 . This suggests that there are other factors, not included in the model, which are important in influencing who gets arrested.

\section{Table 3 about here}

This model suggests that the dichotomous measure of frequency of either high or low offending is not a significant predictor of the likelihood of being arrested. The variables that were significant at the $95 \%$ confidence level or above were the respondent's sex, violent offending, their employment/education status, their having friends in trouble with the police and, importantly for this analysis, their drug use. Self-reported offenders who reported any use of illicit drugs in the past year were nearly two and a half times as likely to report being arrested compared to those who did not report drug use, when taking the influence of the other variables into account.

This dataset and these analyses are inevitably limited in their ability to test the hypothesis that drug using offenders are more likely to be arrested than non-drug using offenders. The relative infrequency of offending reduces the size of the sample available for these analyses. The even rarer occurrence of arrest skews the data. Both of these features reduce the power of the statistical tests and increase the likelihood of 
type II error (i.e. that the analyses fail to demonstrate an association that would be found by a more powerful test). However, this would not change the finding that drug use is associated with an increased risk of arrest, even when taking into account the frequency and type of offending.

The reliance on self-report of offending, arrest, drug use and other variables may also limit the confidence that we have in these analyses. It has been argued that the results of surveys of this kind should be seen as social productions of the interaction between interviewer and respondent (Prior, 2003). However, the designers of the OCJS have been rigorous in adopting methods, such as computer-assisted self interviewing (audio-CASI), which reduce the potential for such bias to occur. And other studies have suggested that drug use and offending are reported reliably in self-report studies, especially in those that use such methods (Harrison, 1997; Thornberry \& Krohn, 2000).

The data is also limited by the age range (10-25) that it covers. But this age range does include the peak ages for offending and covers an age group which includes the bulk of offenders (Budd et al, 2005; Sampson \& Laub, 2005). The most problematic feature of this dataset for the analysis presented here is the low levels of use of heroin and crack reported by the sample. Household surveys are unlikely to sample a representative proportion of such drug users, as they are over-represented in the homeless and prison populations. A different relationship between drug use and arrest may exist for this group. However, these people are highly visible to the police. They are often personally known to police officers and are also recognisable by the physical attributes associated with problematic drug use. From the OCJS data, arrest is rare, 
even for 'serious' offenders, and is better predicted by drug use than by the (dichotomous) frequency of offending. Dependent users of heroin and crack especially may be even more vulnerable to the modes of police discrimination which seem to contribute to the increased risk of arrest for offenders who use drugs, as reported by Rhodes et al's (2007) South Wales sample.

For these, and other reasons, these analyses should be considered as being suggestive rather than confirmatory of the wider relationship between drug use and the likelihood of arrest. What they suggest is that drug users are over-represented in police arrest statistics, by comparison with their representation in the population of recent offenders.

\section{Discussion and conclusion}

This finding is supported by analysis from the Edinburgh Study of Youth Transitions and Crime (ESYTC, McAra \& McVie, 2005). In contrast to the results reported above from the OCJS, the reported frequency of offending was found to be a significant predictor of arrest in the ESYT (perhaps due to the use of a continuous, rather than dichotomous measure of frequency), but drug use also had an independent effect in increasing the probability of having adversarial contact with the police (with an odds ratio of 2) (Ibid: 22). McAra and McVie interpret their results as supporting the disciplinary model of policing, which describes the informal objective of policing as the enforcement of social discipline by punishing, humiliating and enforcing the submission of those groups with whom they are in contact (Choongh, 1998). These groups, made up of low status segments of the working/workless classes, have been 
described by Lee and by Reiner as "police property" (Lee, 1981: 53). They are identified by the "dominant majority" as the proper subjects of social control by the police (Reiner, 2000b: 93). McAra and McVie conclude that police actions are influenced by class bias at the individual level and have the result of "enforcing urban discipline, labelling and keeping under surveillance a group of permanent suspects" (McAra \& McVie, 2005: 28).

The analysis of OCJS data that is presented in table 3 also supports this disciplinary model. The offenders who were most likely to report being arrested in this study were young, unemployed men who had friends who were also in trouble with the police. This increased likelihood of arrest was not just a product of their higher rates of offending, as they were significantly more likely to report arrest even when offending variables were taken into account. Christie (2000: 69) has written that "[ $t$ ]he war on drugs is at the same time a war on the attributes correlated with drug use: being young, being from inner cities, exhibiting life-styles unacceptable to the middle class". It seems from the OCJS analysis that the police do indeed focus their attention on certain social groups in ways which create an over-representation of drug users in arrest statistics. Further research, particularly with hidden populations of problematic drug users, and involving ethnographic examination of police practice towards them would help to confirm whether and how this discrimination occurs.

The over-estimation of the proportion of crime that is drug related has serious consequences, not least for the validity of the DHI. Due to its high weighting, changes in the estimation of crime have the largest potential effect in sensitivity analysis of the DHI. A $20 \%$ change in the proportion of crime that is drug-related would have a $14 \%$ 
effect on the value of the DHI (MacDonald, Tinsley, Collingwood et al., 2005). The OCJS and ESYTC analyses described above suggest that drug users are overrepresented in arrest figures by a factor of at least two. If drug users are twice as likely to be arrested as other offenders (which has also been suggested by an Irish study, [Connolly, 2006]), then this would imply that the weighting of crime in the DHI is seriously overestimated. The value of the DHI has been falling in recent years, largely because of the falling levels of property crime. If these reductions have much less to do with drug users than the DHI suggests, then a misleading impression of the effects of drug policy is being given to Ministers, Parliament and the public.

British drug policy can be seen as a field of argument between those who see drugs as a criminal matter, and others who prefer to see it as an issue of public health (Blackman, 2004; Stevens, 2007). The misleading impression of drug-related crime given by the studies discussed in this article strengthens the hand of those who prefer to respond to drugs as a criminal matter, with whom health professionals have been urged to collaborate in order to justify increases in funding for treatment (Hayes, 2005; Russell, 1994). This supports the shift to coercion that has been evident in the drug policies of the New Labour governments (Duke, 2006; Hunt \& Stevens, 2004; Stimson, 2000). It risks supporting a deviancy amplification spiral, in which drug users are seen as essentially criminal, are therefore targeted for criminalisation by legislators and the police, which leads to reinforcement of the perception of them as essentially criminal. This can be seen as a consequence of "pathologising" studies which focus on captive populations of arrested and treated drug users and therefore suggest the inevitability of loss of control and criminality by drug users (Decorte, 2006). The resultant linkage of drugs to crime justifies, not only increased spending 
on treatment, but the significant increase in the use of imprisonment for drug offenders that has occurred since the early 1990s (Reuter \& Stevens, 2007).

This article does not argue that there is no link between the use of drugs such as heroin and cocaine and other crimes. However, it does argue that current debates and statistics on drug-related crime have exaggerated the extent of this link. This has been done by over-emphasising causality and ignoring the specificity of the link between the use of certain drugs and the commission of certain types of crime. The social, legal and cultural contexts in which both drug use and offending take place have been under-emphasised at the expense of seeing the crime of drug users as drug-driven. And, crucially for attempts to measure the total amount and the trend in drug-related harm, samples of people who have entered treatment or been arrested have been used to estimate drug-related crime, without acknowledging that treatment clients do not form a representative sample of drug users and arrestees do not form a representative sample of offenders.

The past twelve years have seen dramatic reductions in crime. For example, the British Crime Survey has reported a 44\% reduction in property crime since 1995, with particularly steep falls in domestic burglary (Walker, Kershaw, \& Nicholas, 2006). There is little evidence to suggest attendant reductions in the use of heroin, cocaine and crack. The limited evidence available rather suggests that use of these drugs increased until at least the turn of the century and may have stabilised since then (Reuter \& Stevens, 2007) (although there is an ongoing increase in the numbers of young people reported to be using cocaine [Roe \& Man, 2006] and indications of a fall in the incidence of heroin use in some areas [Millar, Gemmell, Hay, Heller, \& 
Donmall, 2006]). It is hard to square the large fall in property crime with historically high levels of use of those drugs that are supposed to be causing the majority of it. It has been claimed that this fall was caused by the large expansion of drug treatment (Hayes, 2006), but it began before this expansion began and even optimistic models of the impact of treatment put a much lower estimate on its effect on crime (Home Office, 2004).

Expansion and improvement of drug treatment should be justified on the basis of its known effects in reducing crime and health problems at the individual level (NICE, 2007a, 2007b, 2007c, 2007d). To argue for treatment on the basis that it will substantially reduce overall crime rates is not supported by the available evidence (Reuter \& Pollack, 2006; Reuter \& Stevens, 2007). Exaggerating the association between drugs and crime risks prolonging the stereotyping and stigmatisation of drug users that has long inhibited rational discussion of drug policy. Such exaggeration is likely to result if simple extrapolations are made from data on treatment and arrestee populations.

\section{Acknowledgements}

The data from the 2004 Offending, Crime and Justice Survey was retrieved from the UK Data Archive at the University of Essex. It was created by the Home Office. Research, Development and Statistics Directorate, National Centre for Social Research and BMRB. The data are Crown Copyright. 
This article has developed from a paper given to the First Annual Conference of the International Society for the Study of Drug Policy (Oslo, March 2007). The author is grateful for the helpful comments and questions he received there. 


\section{References}

Anglin, M.D., \& Speckart, G. (1988). Narcotics use and crime: a multisample, multiperiod analysis. Criminology, 26, 197-233.

Banton, M. (1983). Categorical and Statistical Discrimination. Ethnic and Racial Studies, 6(3), 269-283.

Bennett, T. (1998). Drugs and crime: the results of research on drug testing and interviewing arrestees London: Home Office Research and Statistics Directorate

Bennett, T. (2000). Drugs and crime: the results of the second developmental stage of the NEW-ADAM programme. Home Office Research Study 205. London: Home Office Research and Statistics Directorate.

Bennett, T., Holloway, K., \& Williams, T. (2001). Drug use and offending: summary results from the first year of the $N E W$-ADAM research programme. London: Home Office Research, Development and Statistics Directorate.

Bennett, T., \& Holloway, K. (2005). Disaggregating the Relationship Between Drug Misuse and Crime. The Australian and New Zealand Journal of Criminology, $38(1), 102-121$.

Blackman, S. (2004). Chilling Out: The Cultural Politics of Substance Consumption, Youth and Drug Policy Maidenhead: Open University Press

Boreham, R., Fuller, E., Hills, A., \& Pudney, S. (2006). The Arrestee Survey Annual Report: Oct 2003 - Sept 2004. England and Wales. Home Office Statistical Bulletin 04/06. London: Home Office.

Budd, T., Sharp, C., Weir, G., Wilson, D., \& Owen, N. (2005). Young People and Crime: Findings from the 2004 Offending, Crime and Justice Survey. Home Office Statistical Bulletin 20/05. London: Home Office.

Chambliss, W.J. (1976). The State and Criminal Law. In W.J. Chambliss, \& M. Mankoff (Eds.), Whose Law, What Order? a conflict approach to criminology. New York: John Wiley \& Sons.

Choongh, S. (1998). Policing as social discipline. British Journal of Criminology, 38(4), 623-634.

Christie, N. (2000). Crime Control as Industry: Towards Gulags Western Style. Third edition London: Routledge

Cohen, P.D., \& Sas, A. (1994). Cocaine use in Amsterdam in nondeviant subcultures. Addiction Research, 2(1), 71-94.

Connolly, J. (2006). Drugs and Crime in Ireland. Overview 3. Dublin: Health Research Board.

Da Agra, C. (2002). The complex structures, processes and meanings of the drug/crime relationship. In S. Brochu, C. da Agra, \& M.M. Cousineau (Eds.), Drugs and Crime Deviant Pathways. Aldershot: Ashgate.

Decorte, T. (2006). Presentation: What can we learn from hidden populations?, Common Session on Criminal Justice and Critical Criminology. Ghent: University of Ghent. 
Dodd, T., Nicholas, S., Povey, D., \& Walker, A. (2004). Crime in England and Wales 2003/2004. Home Office Statistical Bulletin 10/04 London: Home Office

Duke, K. (2006). Out of crime and into treatment?: The criminalization of contemporary drug policy since Tackling Drugs Together. Drugs: Education, Prevention and Policy, 13(5), 409-415.

Falk, R.F., \& Tonkin, P. (2001). Soft Modelling the Predictors of Drug Treatment Use. Social Research Update, 32, 1-4.

Fielding, N. (2005). The Police and Social Conflict Abingdon: Routledge-Cavendish

FitzGerald, M., Hough, M., Joseph, I., \& Qureshi, T. (2002). Policing for London Cullompton: Willan Publishing

Godfrey, C., Eaton, G., McDougall, C., \& Culyer, A. (2002). The economic and social costs of Class A drug use in England and Wales, 2000. Home Office Research Study 249. London: Home Office.

Goldstein, P. (1985). The drugs-violence nexus: A tripartite framework. Journal of Drug Issues, 15, 493-506.

Gordon, L., Tinsley, L., Godfrey, C., \& Parrott, S. (2006). The economic and social costs of Class A drug use in England and Wales, 2003/04. In N. Singleton,R. Murray, \& L. Tinsley (Eds.), Measuring different aspects of problem drug use: Methodological developments. London: Home Office.

Gossop, M., Marsden, J., Stewart, D., Lehmann, P., Edwards, C., Wilson, A., \& Segar, G. (1998). Substance use, health and social problems of service users at 54 drug treatment agencies. British Journal of Psychiatry, 173, 166-171.

Gossop, M., Marsden, J., Stewart, D., \& Kidd, T. (2002). Changes in use of crack cocaine after drug misuse treatment: 4- 5 year follow-up results from the National Treatment Outcome Research Study (NTORS). Drug and Alcohol Dependence, 66(1), 21-28.

Gossop, M., Trakada, K., Stewart, D., \& Witton, J. (2006). Levels of conviction following drug treatment: Linking data from the National Treatment Outcome Research Study and the Offenders Index. Findings 275. London: Home Office.

Harrison, L. (1997). The validity of self-reported drug use in survey research: an overview and critique of research methods. In L. Harrison, \& A. Hughes (Eds.), NIDA Research Monograph 167. Rockville, Maryland: National Institute of Drug Abuse.

Hayes, P. (2005). Debate: This house believes that we need more coercive testing and treatment services, National Drug Treatment Conference. London: Exchange Supplies.

Hayes, P. (2006). Presentation: Less crime, not more treatment, ACPO Drugs Conference. Manchester, 21st November 2006: Association of Chief Police Officers.

Holloway, K., Bennett, T., \& Lower, C. (2004). Trends in drug use and offending: the results of the New-ADAM Programme 1999-2002. Findings 219. London: Home Office.

Home Office (2004). Modelling Crime Reduction for the Home Office's Strategic Plan. Home Office Online Report 38/04. London: Home Office. 
Hunt, N., \& Stevens, A. (2004). Whose harm? Harm and the shift from health to coercion in UK drug policy. Social Policy \& Society, 3(4), 333-342.

Karstedt, S., \& Farrall, S. (2006). The Moral Economy of Everyday Crime: Markets, Consumers and Citizens. British Journal of Criminology, 46, 1011-1036.

Lee, J.A. (1981). Some structural aspects of police deviance in relations with minority groups. In C. Shearing (Ed.), Organizational Police Deviance. Toronto: Butterworth.

MacDonald, Z., Tinsley, L., Collingwood, J., Jamieson, P., \& Pudney, S. (2005). Measuring the harm from illegal drugs using the Drug Harm Index. Home Office Online Report 24/05. London: Home Office.

MacDonald, Z., Collingwood, J., \& Gordon, L. (2006). Measuring the harm from illegal drugs using the Drug Harm Index - an update. Home Office Online Report 08/06. London: Home Office.

Macpherson, W. (1999). The Stephen Lawrence Inquiry. London: HMSO.

McAra, L., \& McVie, S. (2005). The usual suspects? Street-life, young people and the police. Criminal Justice, 5(1), 5-36.

McGlothlin, W.H., Anglin, M.D., \& Wilson, D.B. (1977). An evaluation of the California Civil Addict Program. Washington DC: National Institute on Drug Abuse.

Millar, T., Gemmell, I., Hay, G., Heller, R.F., \& Donmall, M. (2006). How well do trends in incidence of heroin use reflect hypothesised trends in prevalence of problem drug use in the North West of England? Addiction Research \& Theory, 14(5), 537-549.

NICE (2007a). Methadone and buprenorphine for the management of opioid dependence. NICE technology appraisal 114. London: National Institute for Health and Clinical Excellence.

NICE (2007b). Naltrexone for the management of opioid dependence. NICE technology appraisal 115. London: National Institute for Health and Clinical Excellence.

NICE (2007c). Opiate detoxification for drug misuse. Draft for consultation. London: National Institute for Health and Clinical Excellence.

NICE (2007d). Psychosocial management of drug misuse. Draft for consultation. London: National Institute for Health and Clinical Excellence.

Nolan, J.L. (2002). Separated by an Uncommon Law: Drug Courts in Great Britain and America. In J.L. Nolan (Ed.), Drug Courts: In Theory and in Practice New York: Aldine de Gruyter.

Parent, I., \& Brochu, S. (2002). Drug/Crime Pathways Among Cocaine Users. In S. Brochu, C. da Agra, \& M.M. Cousineau (Eds.), Drugs and Crime Deviant Pathways. Aldershot: Ashgate.

Prior, L. (2003). Using Documents in Social Research London: Sage

Quetelet, A. (1842). A Treatise on Man Edinburgh: Chambers

Reiner, R. (2000a). Crime and control in Britain. Sociology-the Journal of the British Sociological Association, 34(1), 71-94. 
Reiner, R. (2000b). The Politics of the Police. Third edition Oxford: Oxford University Press

Reuter, P., \& Pollack, H. (2006). How Much Can Treatment Reduce National Drug Problems? Addiction, 101, 341-347.

Reuter, P., \& Stevens, A. (2007). An Analysis of UK Drug Policy. London: UK Drug Policy Commission.

Rhodes, T., Watts, L., Davies, S., Martin, A., Smith, J., Clark, D., Craine, N., \& Lyons, M. (2007). Risk, shame and the public injector: A qualitative study of drug injecting in South Wales. Social Science \& Medicine, 65(3), 572-585.

Roe, S., \& Man, L. (2006). Drug Misuse Declared: Findings from the 2005/06 British Crime Survey. Home Office Statistical Bulletin 15/06. London: Home Office.

Russell, J. (1994). Substance Abuse and Crime (Some Lessons from America). Harkness Fellowship Report. New York: Commonwealth Fund of New York.

Sampson, R.J., \& Laub, J.H. (2005). A Life-Course View of the Development of Crime. The Annals of the American Academy of Political and Social Science, 602(12-45).

Seddon, T. (2006). Drugs, crime and social exclusion: Social context and social theory in British drugs-crime research. British Journal of Criminology, 46(4), 680-703.

Shewan, D., \& Dalgarno, P. (2006). Evidence for controlled heroin use? Low levels of negative health and social outcomes among non-treatment heroin users in Glasgow (Scotland). British Journal of Health Psychology, 10, 33-48.

Singleton, N., Bumpstead, R., O’Brien, M., Lee, A., \& Meltzer, H. (2001). Psychiatric morbidity among adults living in private households, 2000. London: Office for National Statistics.

Singleton, N., Murray, R., \& Tinsley, L. (2006). Measuring different aspects of problem drug use: Methodological developments. Home Office Online Report 16/06. London: Home Office.

Stevens, A. (2006). Presentation: The evidence-policy link: The case of the Drug Treatment and Testing Order, Annual Conference of the British Society of Criminology. Glasgow.

Stevens, A. (2007). When two dark figures collide: Evidence and discourse on drugrelated crime. Critical Social Policy, 27(1), 77-99.

Stimson, G., Hickman, M., \& Turnbull, P.J. (1998). Statistics on misuse of drugs have been misused. British Medical Journal., 317(7169), 1388.

Stimson, G. (2000). 'Blair declares war' or The unhealthy state of British drugs policy. International Journal of Drug Policy, 11(4), 259-264.

Thornberry, T.P., \& Krohn, M.D. (2000). The self-report method for measuring delinquency and crime. In J.E. Samuels (Ed.), Measurement and Analysis of Crime and Justice. Criminal Justice 2000. Volume 4. Washington DC: National Institute of Justice.

Waddington, P.A.J., Stenson, K., \& Don, D. (2004). In Proportion: Race, and Police Stop and Search. British Journal of Criminology, 44(6), 889-914. 
Walker, A., Kershaw, C., \& Nicholas, S. (2006). Crime in England and Wales 2005/06. London: Home Office.

Warburton, H., Turnbull, P.J., \& Hough, M. (2005). Occasional and controlled heroin use: Not a problem? York: Joseph Rowntree Foundation.

Young, J. (1971). The Drugtakers: The Social Meaning of Drug Use London: Paladin

Young, J. (2004). Voodoo criminology and the numbers game. In J. Ferrell, K.

Hayward, W. Morrison, \& M. Presdee (Eds.), Cultural Criminology

Unleashed (pp. 13-27). London: Glasshouse Press.

Zinberg, N.E. (1984). Drug, set, and setting: The basis for controlled intoxicant use. New Haven: Yale University. 


\section{Tables}

\begin{tabular}{lc}
\hline Table 1: Characteristics of self-reported offenders & \\
\hline Characteristics & Proportion \\
\hline Sex & \\
Male & $65.1 \%$ \\
Female & $34.9 \%$ \\
Ethnicity & \\
White & $92.7 \%$ \\
Mixed & $2.6 \%$ \\
Asian or asian British & $2.0 \%$ \\
Black or black British & $1.7 \%$ \\
Other & $0.9 \%$ \\
Age & \\
17-25 & $52.8 \%$ \\
10-16 & $47.2 \%$ \\
Reported offending in last year & \\
Violence & $63.7 \%$ \\
Property & $59.4 \%$ \\
Prolific offending (more than 6 offences in the year) & $28.0 \%$ \\
Reports any illicit drug use & $44.6 \%$ \\
Not in work or education & $8.1 \%$ \\
Parents ever in trouble with the police & $16.9 \%$ \\
Has friends in trouble with the police & $36.7 \%$ \\
Ever truanted from school & $39.3 \%$ \\
Ever excluded from school & $5.6 \%$ \\
\hline
\end{tabular}




\begin{tabular}{|c|c|c|c|}
\hline Characteristics & $\mathrm{n}$ & Proportion arrested & Significance $(p)$ \\
\hline \multicolumn{4}{|l|}{ Sex } \\
\hline Male & 864 & $7.9 \%$ & \multirow[t]{2}{*}{$<0.01$} \\
\hline Female & 463 & $3.5 \%$ & \\
\hline \multicolumn{4}{|l|}{ Age } \\
\hline $17-25$ & 701 & $7.5 \%$ & \multirow[t]{2}{*}{$\mathrm{n} / \mathrm{s}$} \\
\hline $10-16$ & 626 & $5.1 \%$ & \\
\hline \multicolumn{4}{|l|}{ Ethnicity* } \\
\hline Black, black British or mixed & 58 & $10.1 \%$ & \multirow[t]{2}{*}{ * } \\
\hline Other & 1269 & $6.1 \%$ & \\
\hline \multicolumn{4}{|l|}{ Violent offending } \\
\hline Reports violent offending & 835 & $7.9 \%$ & \multirow[t]{2}{*}{$<0.01$} \\
\hline Does not report violent offending & 476 & $3.6 \%$ & \\
\hline \multicolumn{4}{|l|}{ Property offending } \\
\hline Reports property offending & 751 & $6.7 \%$ & \multirow[t]{2}{*}{$\mathrm{n} / \mathrm{s}$} \\
\hline Does not report property offending & 513 & $6.3 \%$ & \\
\hline \multicolumn{4}{|l|}{ Frequency of offending } \\
\hline Reports prolific offending & 372 & $8.9 \%$ & \multirow[t]{2}{*}{$<0.05$} \\
\hline Does not report prolific offending & 955 & $5.3 \%$ & \\
\hline \multicolumn{4}{|l|}{ Illicit drug use } \\
\hline Reports any drug use & 578 & $9.2 \%$ & \multirow[t]{2}{*}{$<0.0005$} \\
\hline Does not report any drug use & 719 & $4.0 \%$ & \\
\hline \multicolumn{4}{|l|}{ Employment status } \\
\hline Unemployed or inactive & 107 & $18.1 \%$ & \multirow[t]{2}{*}{$<0.0005$} \\
\hline Employed or in education & 1220 & $5.3 \%$ & \\
\hline \multicolumn{4}{|l|}{ Parents contact with police } \\
\hline Parents ever in trouble & 199 & $6.5 \%$ & \multirow[t]{2}{*}{$\mathrm{n} / \mathrm{s}$} \\
\hline Parents never in trouble & 978 & $5.2 \%$ & \\
\hline \multicolumn{4}{|l|}{ Friends' police contact in last 12 months } \\
\hline Any friends in trouble with police & 451 & $11.8 \%$ & \multirow[t]{2}{*}{$<0.0005$} \\
\hline No friends in trouble with police & 777 & $3.5 \%$ & \\
\hline \multicolumn{4}{|l|}{ Truanting from school } \\
\hline Ever truanted & 509 & $9.7 \%$ & \multirow[t]{2}{*}{$<0.0005$} \\
\hline Never truanted & 785 & $4.1 \%$ & \\
\hline \multicolumn{4}{|l|}{ Exclusion from school* } \\
\hline Ever excluded & 74 & $11.6 \%$ & \multirow[t]{2}{*}{ * } \\
\hline Never excluded & 1239 & $5.8 \%$ & \\
\hline
\end{tabular}

* In cross-tabulation of these variables with arrest, one of the expected cell counts was less than 5. 
Table 3: Logistic regression of reporting being arrested in previous year $(n=1,020)$

\begin{tabular}{lccc}
\hline & Odds ratio & $95 \%$ Confidence Interval & Significance $(\mathrm{p})$ \\
\hline Sex is male & 3.50 & $1.63-7.49$ & $<0.01$ \\
$\begin{array}{l}\text { Any property offending } \\
\text { Any violent offending }\end{array}$ & 2.88 & $1.43-5.83$ & $<0.001$ \\
Prolific offending & & & \\
Any drug use in previous year & 2.46 & $1.32-4.6$ & $<0.01$ \\
$\begin{array}{l}\text { Friends in trouble with police } \\
\text { Not in work or education }\end{array}$ & 3.08 & $1.7-5.6$ & $<0.001$ \\
Ever truanted & 5.99 & $2.78-12.98$ & $<0.0005$ \\
\hline
\end{tabular}

Grey text indicates variables that were excluded as they did not contribute significantly to the model. 